\title{
Aspectos psicossociais da sexualidade na adolescência: diálogos e aprendizagem na escola
}

\section{Psychosocial aspects of sexuality in adolescence: dialogue and learning in school}

\author{
Ana Karla da Silva Freire ${ }^{1}$, Mônica Cecília Pimentel de $\mathrm{Melo}^{2}$, Michelângela Pinto Vieira ${ }^{3}$, \\ Isabella Mendes Gomes ${ }^{4}$, Jéssica Lopes Gomes ${ }^{4}$, Deolindo de Sousa Ribamar ${ }^{4}$, Vitória Silva \\ Coêlho ${ }^{4}$, Albertino José Ferreira Neto ${ }^{4}$, Keylla Karinna Marques ${ }^{3}$, Gustavo Elias da Silva ${ }^{4}$, Félix \\ Alexandre Antunes Soares ${ }^{5}$, Mateus Mattiuzi da Costa ${ }^{6}$
}

\section{Resumo}

A sexualidade se manifesta com mais intensidade na adolescência, fase em que há transformações intensas. Na escola, faltam espaços de discussão sobre a temática. Pretendeu-se compreender os aspectos psicossociais da sexualidade de adolescentes, revelados através do desenvolvimento de oficinas. Tratase de estudo qualitativo, baseado na pesquisa-ação e na metodologia da problematização, realizado em uma escola pública do município de Juazeiro/BA, através da oficina crítico-emancipatória "Diz aí, professor, pois quero curtir a vida!", com adolescentes do Ensino Fundamental II e Médio. Os resultados indicam que muitos adolescentes têm receio de conversar com a família por acreditarem que serão repreendidos, bem como têm pouco conhecimento sobre Doenças Sexualmente Transmissíveis e sobre direitos sexuais e reprodutivos. A homossexualidade foi o tema mais polêmico e com opiniões divergentes. Logo, percebe-se a necessidade de enfatizar a educação sexual e reprodutiva nas escolas, abordando o tema de forma alternativa ao modelo tradicional. Os tabus, as crenças e os mitos referentes à sexualidade na adolescência precisam ser discutidos por meio de estratégias que reconheçam os adolescentes como atuantes. Além disso, é importante uma aprendizagem mais reflexiva, com princípios mais humanos, no que concerne à sexualidade, diminuindo o estigma, a discriminação e a violência na sociedade.

Palavras chave: Sexualidade. Adolescente. Aprendizagem. Educação sexual.

\begin{abstract}
The sexuality manifests itself more strongly in adolescence, a phase were there are intense transformations. At school, there is no room for discussion on the subject. The aim of this study was to understand the psychosocial aspects of teenager's sexuality, revealed through the development of workshops. A qualitative study, based on action research and problem-solving methodology, performed in a public school in the city of Juazeiro, Bahia, through the critical-emancipatory workshop "Tell me teacher, because I want to enjoy life!" with First and Secondary School Students. The results indicate that many teenagers are afraid to talk to their family because they believe they will be reprimanded, as well as have little knowledge about Sexually Transmitted Diseases and about sexual and reproductive rights. The homosexuality was the most controversial subject and with divergent opinions. Therefore, it is necessary to emphasize sexual and reproductive education in schools, approaching the theme in an alternative way to the traditional model. The taboos, beliefs and myths regarding sexuality in adolescence
\end{abstract}

\footnotetext{
${ }^{1}$ Especialização em Enfermagem do Trabalho. Residente em Saúde Mental pela Universidade Federal do Vale do São Francisco; Petrolina, Pernambuco, Brasil.

2 Doutoranda em Educação em Ciências, Química da Vida e Saúde com associação de IES UFRGS/UFSM/FURG. Colegiado de Enfermagem da Universidade Federal do Vale do São Francisco; Petrolina, Pernambuco, Brasil. E-mail: monquinamelo@gmail.com

3 Graduanda em Enfermagem pela Universidade Federal do Vale do São Francisco, Petrolina, Pernambuco, Brasil.

${ }^{4}$ Graduando(a) em Medicina pela Universidade Federal do Vale do São Francisco, Petrolina, Pernambuco, Brasil.

${ }^{5}$ Doutorado em Ciências Biológicas (Bioquímica) pela Universidade Federal do Rio Grande do Sul. Docente da Universidade Federal de Santa Maria; Santa Maria, Rio Grande do Sul, Brasil.

${ }^{6}$ Doutorado em Biologia Celular e Molecular pela Universidade Federal do Rio Grande do Sul. Docente da Universidade Federal do Vale do São Francisco; Petrolina, Pernambuco, Brasil.
} 
need to be discussed through strategies that recognize adolescents as performers. In addition, a more reflective learning with more humane principles is important in relation to sexuality, reducing stigma, discrimination and violence in society.

Keyword: Sexuality. Teenager. Learning. Sexual education.

\section{Introdução}

A adolescência é uma fase do desenvolvimento humano em continuidade ao processo dinâmico da evolução, a qual é evidenciada por grandes transformações, tais como o crescimento biológico e as mudanças psicossociais e cognitivas (PAPALIA; FELDMAN, 2013). Como nessa fase ocorre a transição entre infância e vida adulta, há algumas alterações biológicas, psicológicas e sociais intensas que normalmente acontecem acompanhadas por curiosidade e necessidade de autoafirmação, peculiares em meio ao turbilhão de transformações dessa etapa da vida (MOREIRA; FOLMER, 2015).

A vivência da sexualidade está presente em todas as fases da vida de mulheres e homens, começando no nascimento e estendendo-se até o momento da morte (MACEDO et al., 2013). Entretanto, é na adolescência que a sexualidade tem o seu início movido pela curiosidade, desejo e necessidade de afeto ou independência, manifestando-se de forma exploratória e permitindo a descoberta de desejos e potencialidades, nessa relação com o novo corpo (SILVA JÚNIOR et al., 2016). Porém, é válido ressaltar que a sexualidade não surge na adolescência, mas se complementa nela. Todavia, como a busca por autonomia e reconhecimento social se dá nessa fase, e o contexto de inserção do fenômeno está inserido em uma cultura em que os tempos são de conteúdos erotizados e de acesso rápido às informações, o adolescente se torna um mero expectador alienante da sua própria sexualidade (MELO; COELHO, 2011).

Nesse tocante, os pais sentem dificuldades em abordar naturalmente a sexualidade com os seus filhos, passando a responsabilidade primordial para a escola e, dessa forma, eximindo-se do papel de também educadores. Entretanto, nem sempre a instituição está preparada para assumir a demanda, deixando os adolescentes despreparados e vulneráveis às opiniões de amigos e aos meios de comunicação (COSTA et al., 2014; NERY et al., 2015; PIROTTA et al., 2013).

Por isso, é fundamental uma atenção especial sobre o tema, no âmbito escolar, pois os aspectos psicossociais acerca do exercício da sexualidade adolescente podem implicar trajetórias de vida que levem ao enfrentamento de situações como gravidez, doenças sexualmente transmissíveis (DSTs), aborto etc. Dessa forma, postula-se a necessidade de um aporte de profissionais da saúde e da educação para intervir nas prioridades que envolvem a sexualidade, destacando as situações de vulnerabilização dos adolescentes (QUIRINO; ROCHA, 2012).

Para tanto, ao se tecer alguns horizontes e perspectivas de trabalho juvenil para a construção de autonomia, conhecimento e escolhas responsáveis, as atividades grupais, como as oficinas, constituemse em uma forma privilegiada de facilitar a expressão dos adolescentes (FREIRE, 1996). Portanto, como os aspectos psicossociais exercem papel fundamental na sexualidade dos adolescentes e as oficinas destacamse como uma possibilidade de expressão, ressalta-se o seguinte objeto de estudo: aspectos psicossociais da sexualidade através do diálogo com adolescentes. Como questão de pesquisa, tem-se: como se revelam os aspectos psicossociais acerca da sexualidade, segundo a ótica de alunos do Ensino Fundamental II e Médio, participantes de oficinas crítico-emancipatórias?

Posto isso, pretendeu-se compreender os aspectos psicossociais da sexualidade de adolescentes de uma escola pública do município de Juazeiro/BA, revelados através do desenvolvimento de oficinas reflexivas. Nesse sentido, a relevância na compreensão desses aspectos desvela o modo de ver, cuidar e pensar sobre a sexualidade nessa fase de vida, em meio à cultura, à condição socioeconômica e à historicidade nos quais o adolescente está inserido, retratados em espaços dialógicos como as oficinas.

\section{Material e Método}

Trata-se de estudo qualitativo e descritivo, do tipo relato de experiência (MINAYO; DESLANDES; GOMES, 2012), com estratégia resolutiva de problemas baseada na pesquisa-ação (FRANCO, 2010) e na metodologia da problematização (FREIRE, 1996), sendo esta última considerada ferramenta estratégica para a construção do conhecimento a partir das experiências, informações e vivências trazidas.

Seguindo uma tendência em desenvolver potenciais soluções de aperfeiçoamento da prática em saúde, o 
estudo pretendeu empregar a pesquisa-ação enquanto ferramenta resolutiva na identificação de problemas. Define-se como uma forma de pesquisa na qual se busca trabalhar com, para e por pessoas, em vez de somente pesquisar sobre (FRANCO, 2010).

A pesquisa ocorreu em uma escola pública da rede estadual de ensino da Bahia, Brasil, com alunos adolescentes dos turnos matutino e vespertino, entre 15 e 19 anos, do Ensino Fundamental II e Médio, em uma lógica de intervenção no lócus de estudo, com ações educativas em saúde, através de uma oficina sobre sexualidade, intitulada "Diz aí, professor, pois quero curtir a vida!"

O lócus foi escolhido por ter sido campo de atuação da Residência Multiprofissional em Saúde da Família (RSMF/UNIVASF), no período de sondagem para a realização do estudo. Nesse mesmo período, os professores relataram, durante a visita, a realidade vivenciada por muitos adolescentes, como a gravidez.

A coleta do material empírico foi realizada pela equipe de iniciação científica, composta por todos os autores do estudo, sendo estes estudantes da residência e da graduação em Enfermagem e Medicina. Utilizouse a técnica de oficina crítico-emancipatória. As oficinas são práticas educativas que valorizam a discussão e as experiências em grupo, estimulando, assim, o empoderamento e a autonomia nas decisões de forma responsável, e não manipuladora.

$\mathrm{O}$ seu desenvolvimento prioriza as atividades grupais, promovendo o conhecimento ou aprimoramento de determinado assunto, sem que haja a reprodução de conceitos pré-estabelecidos (FONSECA; AMARAL, 2012). Suas fases são estruturadas na seguinte organização: apresentação e integração; desenvolvimento do tema; socialização das experiências; síntese; avaliação; e descontração/ relaxamento, permitindo ao público-alvo a troca de experiências e respostas para suas necessidades, pilares fundamentais na construção da autonomia e de posturas educacionais responsáveis (FONSECA; AMARAL, 2012).

Desse modo, a oficina denominada "Diz aí, professor, pois quero curtir a vida!" foi disponibilizada aos alunos em duas datas, 11 e 16 de junho de 2015 , nos turnos vespertino e matutino, respectivamente, com duração de $4 \mathrm{~h}$ para cada data. Essas datas foram agendadas previamente com a escola, pois se firmou a liberação das aulas nesses dias e horários, para que os adolescentes pudessem escolher o dia que melhor lhes conviesse, de acordo com o seu turno escolar, e, assim, para que o estudo conseguisse obter o maior número possível de participantes.

Pela perspectiva da análise qualitativa, foi utilizada a amostra não probabilística, do tipo intencional, por adesão voluntária dos estudantes, mediante preenchimento do Termo de Consentimento Livre e Esclarecido. Para os menores de idade, a inclusão dos participantes se deu por meio da autorização dos pais ou responsáveis, através do mesmo termo, além da assinatura do Termo de Assentimento, confirmando que o menor expressava o desejo de participar da pesquisa.

Os alunos foram contatados e convidados a participar da atividade uma semana antes do início da primeira oficina, por meio de convite verbal feito em sala de aula, em cada turma, pela equipe executora. Esse período foi utilizado para que houvesse tempo hábil para a autorização dos responsáveis pelos menores e para o recolhimento dos termos. Assim, no dia 11, à tarde, participaram 13 alunos (5 meninos e 8 meninas) e, no dia 16, pela manhã, contou-se com a presença de 20 estudantes (9 meninos e 11 meninas), sendo que, na primeira oficina, participaram apenas alunos do turno matutino e, na segunda oficina, os alunos do turno vespertino de forma a abranger o maior número possível de participantes diferentes.

Foi estabelecido um roteiro metodológico para o andamento das atividades e dinâmicas pretendidas na oficina. Em vista disso, a oficina iniciou-se com o acolhimento aos participantes, em que todos foram orientados a ficar em círculo, na posição de sua preferência, sem distinção de série, idade ou sexo, pois quanto mais heterogêneo é o grupo de adolescentes, melhores são as trocas (BRASIL, 2007a; BRASIL, 2007b). Notou-se nesse momento certa ansiedade por parte deles, uma vez que, para muitos ali, era a primeira experiência em grupo para tratar de um assunto tão permeado por tabus, como a sexualidade.

Para deixar os alunos mais relaxados, visando facilitar a socialização entre os presentes, começouse a primeira dinâmica, na qual os alunos deveriam formar um círculo e escrever no anverso de um pedaço de papel uma pergunta sobre qualquer tema desejado e, no verso, uma resposta para a pergunta que foi criada. Em seguida, os alunos dobraram seus papéis e os colocaram em uma sacola. Durante esse momento, os papéis foram balançados na sacola e foi pedido para que cada aluno retirasse um papel e formasse um par de sua livre escolha. Após esse momento, cada aluno teve a oportunidade de ler a pergunta que pegou e a 
resposta que estava atrás do papel. Isso desencadeou momentos de surpresa, descontração e gargalhadas em relação a algumas perguntas e respostas que foram mencionadas. Notou-se que alguns alunos já estavam mais ativos e demonstrando sentir-se bem naquele ambiente, interagindo mais positivamente, tanto em relação aos outros alunos como com os monitores da oficina.

A segunda dinâmica da oficina foi a do Semáforo, cujo objetivo era identificar as dificuldades dos adolescentes e auxiliá-los quanto aos temas em que eles tinham maior interesse a respeito da temática sexualidade. Solicitou-se aos alunos que procurassem pensar em assuntos que eles não se sentissem confortáveis em discutir com os pais, bem como assuntos não tratados pelos professores em sala de aula.

Dessa forma, foi solicitado que escrevessem em três fichas de papel uma palavra que correspondesse a um tema de interesse próprio sobre sexualidade. Depois, cada participante distribuiu as fichas pelos círculos com as cores ou sinais do semáforo, de acordo com o grau de dificuldade que sentiam ao debater sobre os temas. O sinal vermelho representava muita dificuldade; o amarelo, dificuldade média; e o verde significava pouca dificuldade. De forma unânime, todos responderam que gostariam de começar pelas palavras da cor vermelha. Estas foram lidas pelos alunos à medida que o monitor solicitava a leitura e, assim, cada um respondia individualmente e/ ou em grupo conforme a discussão sobre a temática acontecia. O monitor mediava a organização da leitura das palavras e a discussão. A dinâmica procurou promover a escuta e a dialogicidade, oportunizando aos adolescentes escolhas e posturas responsáveis ao tratar de temas sobre sexualidade em espaços como a família e a escola (FREIRE, 1996).

Reproduziu-se, a posteriori, o vídeo "X-Salada e Pão com Ovo" (ECOS COMUNICAÇÃO EM SEXUALIDADE, 2013), que aborda diversas situações para debater os direitos sexuais e reprodutivos dos adolescentes, os quais a maioria desconhece. Esse vídeo dá ênfase aos direitos sexuais e aos direitos reprodutivos de adolescentes e jovens, com a perspectiva de erradicar as discriminações relativas a gênero, orientação sexual, idade, raça/etnia, deficiências e classe social.

Realizou-se, posteriormente à terceira dinâmica, com temáticas relacionadas aos direitos sexuais e reprodutivos, um tabuleiro interativo com perguntas simples para fins de aferição e discussão sobre esses direitos. O objetivo foi discutir o tema à medida que os questionamentos de cada casa do tabuleiro foram surgindo. Os adolescentes foram divididos em grupos e elegeram-se representantes para cada um dos grupos, de forma a construir uma representação à medida que as perguntas fossem surgindo. Assim, o representante de cada grupo expunha uma dúvida de cada vez referente à temática, no momento solicitado, e o do outro grupo falava posteriormente. Dessa forma, as dúvidas surgidas em cada grupo foram sendo sanadas conforme as perguntas estavam sendo respondidas.

Na sequência, foi realizada a quarta dinâmica, com a temática referente ao uso correto do preservativo e de outros métodos contraceptivos. Foram selecionados dois casais, sendo um para colocar e retirar o preservativo da prótese masculina e o outro para fazer o mesmo com o feminino. Depois, inverteramse os papéis para a colocação dos preservativos nas respectivas próteses. Vale ressaltar que a escolha dos casais foi por livre arbítrio, para quem se pronunciasse e quisesse participar.

Para finalizar a oficina, o vídeo "Bonezinho Vermelho" (ECOS COMUNICAÇÃO EM SEXUALIDADE, 2014) foi exibido. Retrata temas da sexualidade na adolescência, como métodos contraceptivos, contracepção de emergência, gravidez na adolescência e participação masculina.

A coleta do material foi realizada mediante registro em um celular, com função de gravador, pelo qual foi possível adquirir $8 \mathrm{~h}$ de gravação de áudio, seguindose, posteriormente, com a transcrição das oficinas. As correções de linguagem realizadas nas falas foram apenas de exclusão dos vícios de linguagem, a exemplo de "né" e "num é".

Os alunos foram identificados com as letras sequenciais do alfabeto, a partir da ordem de cada fala. A pesquisa foi autorizada pelo Comitê de Ética e Deontologia em Estudos e Pesquisas da Universidade Federal do Vale do São Francisco (CEDEP/UNIVASF), registro $n^{\circ} 0014 / 250614$.

\section{Resultados}

Participaram da oficina 33 estudantes, tendo estes entre 15 e 19 anos, do Ensino Fundamental II e Médio. A realização da oficina resultou em algumas falas importantes, quando o aluno lia o papel retirado pelo colega que o estava acompanhando, gerando, dessa forma, perguntas e respostas aleatórias. Tais falas podem ser evidenciadas a seguir: 
Pergunta: Por que nunca beijaram na vida? (Aluno A)

Resposta: Porque é um mistério. (Aluno C)

Pergunta: Por que os jovens de hoje estão em

um relacionamento ou gostam de namorar cedo? (Aluno D)

Resposta: Viajar. (Aluno B)

Pergunta: Fazer sexo com 11 anos é certo?

(Aluno F)

Resposta: É amor. (Aluno E)

Pergunta: Pode pegar DST através do beijo? (Aluno H)

Resposta: Não sei. (Aluno G)

Na outra dinâmica realizada, a do Semáforo, um dos assuntos mais explorados foi a virgindade, considerada um tema de difícil abordagem, que requer confiança para ser compartilhado, principalmente entre amigos, e considerada sem hora certa para se perder, como pode ser percebido nas frases mencionadas a seguir:

Eu acho difícil. (Aluna A)

Eu também. (Aluna B)

Também acho. (Aluna C)

Ao tratarem da sexualidade nessa dinâmica e, por conseguinte, da relação sexual como uma consequência dessa manifestação, os adolescentes expressaram medo de se sentirem reprimidos e impedidos pelos familiares. Tudo isso porque, para os alunos, seus pais os consideram muito jovens e não permitem que cometam erros muito cedo. Entretanto, os alunos sentem a necessidade de errar para aprender com os próprios erros, assim como mencionado na seguinte fala:

A gente tem que aprender com nossos erros e acertos, mas as mães não querem nos deixar errar. Mas, como é que a gente vai aprender sem errar? (Aluna $\mathrm{R}$ )

Outro ponto destacado pelos adolescentes foi a dificuldade de diálogo com os pais. Diante da complexidade e dificuldade para conversar com eles, surgiram nessa dinâmica, primordialmente, os amigos e a internet, uma vez que a família, na maioria das vezes, não entende as aflições e anseios surgidos nessa fase da vida e julgam logo que é algo errado, repreendendo-os em seguida, após alguma pergunta sobre o tema.

Não gosto de falar da minha intimidade com minha mãe, eu prefiro falar com as amigas ou minha prima. (Aluna D)

Converso com os amigos. (Aluno E)
Ainda na dinâmica do Semáforo, surgiu o tema das DSTs. Ao tratarem sobre estas, os alunos demonstraram pouco conhecimento sobre o assunto e a única DST lembrada foi a AIDS, como demonstrado nas falas a seguir:

Aquelas "perebas" feias. (Aluna G)

Só sei de AIDS. (Aluna I)

Em relação às demais doenças, já ouviram falar, mas gostariam de aprender mais acerca delas. Exemplo:

Eu já vi um pouco, quero saber mais. (Aluna $\mathrm{H}$ )

Outro assunto que foi retratado ainda pela mesma dinâmica e que despertou polêmica e opiniões diferentes foi a homossexualidade. Alguns deles tiveram suas opiniões envolvidas pelo discurso religioso, ressaltando a contrariedade a essa prática, como demonstrado a seguir:

Eu acho que é errado. Só eu que acho que é errado, gente? Por que Deus criou o homem e a mulher. Como pode, se Deus fez o homem, ele querer ser mulher? Por que Deus criou Adão e Eva, e eles foram tendo filhos e tal. (Aluna A) Eu acho que é errado [a homossexualidade]. (Aluna A)

Eu acho que não é certo, não. (Aluna B)

A reprodução do vídeo "X-Salada e Pão com Ovo" teve receptividade e aceitação positivas, gerando relatos como:

\section{Massa! (Aluna M)}

Interessante! (Aluno N)

Outro ponto de destaque que surgiu no vídeo foi relacionado aos direitos sexuais e reprodutivos dos adolescentes, como, por exemplo, o direito à continuidade dos estudos às grávidas e puérperas adolescentes; o acesso gratuito e sem discriminação aos métodos contraceptivos; a privacidade e o sigilo nos atendimentos em saúde; o direito de escolher se quer ou não quer ter relação sexual; o direito de expressar livremente sua orientação sexual: heterossexualidade, homossexualidade, bissexualidade; entre outros.

Ainda como parte integrante desse momento de discussão, surgiram relatos que demonstraram desconhecimento sobre alguns desses direitos sexuais e reprodutivos dos adolescentes:

Hum, direito de ter desejo. (Aluna $\mathrm{H}$ )

Porque no mundo tem mais mulher, né? E os homens tão virando 'viado'. (Aluna F)

Ademais, após o início da dinâmica com o tabuleiro interativo com perguntas simples para fins de aferição 
e discussão, surgiram vários temas relacionados, entre eles, o aborto.

Sobre o aborto, os alunos demonstraram algum conhecimento, como nas falas a seguir:

[...] o aborto espontâneo é quando o corpo expulsa, a pessoa não segura, aí, não é crime. (Aluna $\mathrm{J}$ )

Se ela perdeu, ela não teve culpa, mas ela tirar uma criança é crime. (Aluna L)

Na hora de colocar os preservativos nas próteses, muitos foram os questionamentos, mas foi possível perceber um maior déficit de conhecimento no que se refere à camisinha feminina:

Por que é desse tamanho? (Aluna Y)

A feminina tem em posto ou só na farmácia? (Aluna B)

Mas como é que dobra? Eu quero saber. (Aluna E)

Mas se não for desse tamanho? Como é que faz? (Aluna F)

Sim. E como é que tira? Tem ensinando como é que tira? (Aluna $\mathrm{H}$ )

Em relação ao preservativo masculino, houve um conhecimento maior sobre seu uso, principalmente, na hora da colocação na prótese:

Eu estou aqui com meu namorado, ele vai usar camisinha. A gente quer estar muito prevenido. (Aluna $\mathrm{H}$ )

Posteriormente, para finalização da oficina, após a exibição do vídeo "Bonezinho Vermelho", o momento foi para dúvidas e comentários:

$\mathrm{Na}$ verdade eu aprendi muito com o vídeo. (Aluna V)

Não, não estou [com dúvidas], queria ficar mais. (Aluna T)

\section{Discussão}

Durante a realização da oficina, percebeu-se que os alunos sentiram-se à vontade, interagindo de forma positiva. Como roteiro metodológico de uma oficina, faz-se importante "aquecer" o interesse do grupo para promover motivação em participar (BRASIL, 2007a; BRASIL, 2007b).
Além disso, mesmo pedindo para os adolescentes fazerem perguntas relacionadas a qualquer tema, eles tenderam a abordar temas ligados à sexualidade. Isso denota que apresentam grandes dúvidas sobre temáticas relacionadas a comportamento sexual e DSTs (MANTOVANI et al., 2014).

Já na dinâmica do Semáforo, percebeu-se, de acordo com as falas, que o diálogo com a família sobre o assunto ainda é permeado pelo silêncio, proibição e muitos tabus. Quando há abertura, são as mães as protagonistas da conversa, mas, muitas vezes, esse diálogo não se mantém como um canal aberto, com uma escuta compreensível. Vale ressaltar que quanto menos os filhos são ouvidos e compreendidos pelos pais, menor a idade da iniciação sexual (VANZIN et al., 2013).

Sobre a dificuldade de diálogo com os pais, por estes não saberem abordar o tema com os seus filhos, ou por repetirem a mesma conduta de seus pais, da falta de diálogo, os adolescentes procuram de alguma forma evitar o assunto ou o abordam com muita dificuldade. Desse modo, torna-se menos complexo transferir essa responsabilidade para a escola (SAVEGNAGO; ARPINI, 2014). Uma pesquisa realizada no ano de 2010 evidenciou que dois terços dos adolescentes entrevistados nunca falaram sobre esse tema com os pais (JONES, 2010).

Assim, a falta de um diálogo presencial e esclarecedor com a família, conforme os adolescentes, provoca impacto negativo na sexualidade desses jovens, os quais procuram suprir as curiosidades com a internet, com revistas de foco juvenil, com os seus próprios parceiros ou com pessoas desconhecidas, consideradas "descoladas" pelos adolescentes (COSTA et al., 2014; NERY et al., 2015). Advogase que essa busca de informações não é segura, podendo desenvolver comportamentos distorcidos e vulneráveis, além da diminuição da afetividade e intimidade no contexto familiar, causada pela ausência de diálogos esclarecedores e construtivos (COSTA et al., 2014; NERY et al., 2015).

Em relação às doenças sexualmente transmissíveis abordadas pelos alunos ainda na dinâmica do Semáforo, foi esclarecido o que cada um deveria fazer caso suspeitasse de algo estranho no corpo, principalmente nos órgãos genitais, como o aparecimento de verrugas, erupções, corrimento genital, incentivando-os quanto à necessidade de ida à unidade básica de saúde. Tais orientações foram bem recebidas pelos alunos, percebidas pela atenção que cada um despendia. 
Essa realidade mostra-se presente em outros estudos cujos resultados são insatisfatórios em relação ao conhecimento geral sobre as DSTs/AIDS, o que expõe os jovens aos riscos de infecção sexual (COELHO et al., 2011).

Sobre a homossexualidade retratada pelos alunos na dinâmica, é importante evidenciar que a sexualidade ainda é um tema pouco discutido, seja na família, seja na escola, e isso faz com que os jovens permaneçam desinformados sobre as práticas sexuais, sendo necessário compreender como os mesmos lidam com a formação de conceitos na perspectiva da sexualidade, comparando o grau de informação dos adolescentes com as influências na formação de seus conceitos (MAROLA; SANCHES; CARDOSO, 2011). Por isso, foi colocado pela equipe, no decorrer da oficina, que esse tema deve ser tratado com muito respeito, uma vez que cada pessoa tem livre arbítrio para escolher sua opção sexual conforme o seu desejo.

Os depoimentos expostos aqui convergem com outros trabalhos, segundo os quais muitos jovens compreendem a homossexualidade como anormal, não natural ou pecado (SILVA; PAIVA; PARKER, 2013). Os estereótipos que envolvem a atribuição de masculinidade ou de feminilidade, como o título de mulher masculinizada ou homem afeminado a homossexuais, acabam reproduzindo os pensamentos preconceituosos e discriminantes de características que são próprias de cada indivíduo (SILVA, 2013).

Isso revela a necessidade de desconstrução do preconceito, principalmente por meio da educação (SILVA; PAIVA; PARKER, 2013). Sendo assim, a educação sexual tem o objetivo de levantar argumentos sobre a temática, não no sentido de problematizá-la, mas sim de demonstrar evidências para que seja incluída como algo existente e predominante na história e na cultura da sociedade, apresentando conhecimentos para a compreensão das crenças e preconceitos que surgiram ao longo da história (MACEDO et al., 2013).

Como utilização de técnica lúdica e interativa, a exposição de vídeos educativos facilita as discussões a partir das experiências individuais, compreendendo que o indivíduo é o sujeito ativo de seu próprio conhecimento e, portanto, constrói seus significados e define suas percepções da realidade (FREIRE, 1996).

Sobre a repercussão gerada pela reprodução do vídeo "X-Salada e Pão com Ovo" (ECOS COMUNICAÇÃO EM SEXUALIDADE, 2013), é possível perceber que a Lei Federal $n^{\circ} 6.202 / 75$ garante à gestante estudante o direito de continuar os estudos em seu domicílio após o oitavo mês de gestação, bem como no período da licença-maternidade, podendo esse prazo ser estendido, mediante comprovação médica (BRASIL, 1975). Essa atribuição legal é essencial para muitas adolescentes que engravidam antes dos 20 anos, pois é um período considerado de escolarização (MORAES; VITALLE, 2012).

É fato que a gestação altera a vida de muitos adolescentes e que, por isso, mediante o contexto socioeconômico e cultural de inserção desses jovens, pode ocorrer uma tendência a abandonar os estudos. A garantia de término do ano letivo é muito importante, uma vez que é uma forma de incentivo para a conclusão dos estudos, com consequentes perspectivas de oportunidades sociais melhores, como emprego e renda (MORAES; VITALLE, 2012).

É papel dos serviços de saúde garantir acesso a informações e educação em saúde sexual e reprodutiva, através de meios e métodos que auxiliem os adolescentes a evitarem uma gravidez não planejada e a prevenirem-se contra DSTs/AIDS. À vista disso, o atendimento, antes mesmo do início das atividades sexuais, para ajudá-los a lidar com a sua sexualidade de forma positiva e responsável, incentivando comportamentos de prevenção e de autocuidado, deverá ocorrer nos moldes do sigilo e da privacidade (BRASIL, 2009).

Os direitos sexuais e reprodutivos dos adolescentes, muitas vezes, não são respeitados nem assegurados, em razão da sua discussão ser relativamente nova no mundo, principalmente no que concerne à orientação sexual. Mas é imprescindível uma interação entre saúde, educação e família, através de uma melhor vinculação e comunicação entre eles, para a garantia legal desses direitos, rejeitando todas as formas de violência, bem como atitudes discriminatórias contra homossexuais e a ridicularização de adolescentes que não sejam sexualmente ativos (BRASIL, 2009; HEILBORN, 2012; MORAES; VITALLE, 2012).

Assim, todos devem ter o direito de viver e expressar livremente a sexualidade sem violência, discriminações e imposições, com respeito pleno pelo corpo do(a) parceiro(a), além do direito de escolha desse(a) parceiro(a) sexual (BRASIL, 2009; HEILBORN, 2012; MORAES; VITALLE, 2012).

A dinâmica com o tabuleiro trouxe algumas análises, sendo uma delas o aborto sob condições de risco, que se torna mais evidente entre as adolescentes do que nas mulheres adultas, uma vez que, carregadas por medo, culpa, censura, vergonha, encontram, nesse recurso, a 
única saída para a solução dos seus problemas. Essa decisão, muitas vezes, é vivida de forma solitária e clandestina, ou sob pressão dos parceiros ou dos familiares, e, ao decidirem interromper a gravidez, utilizam quaisquer recursos que tenham à mão (MELO; COELHO, 2011).

Sobre o despreparo percebido na colocação dos preservativos masculino e feminino, é importante evidenciar que as adolescentes estão mais propensas às doenças e ao óbito por aborto clandestino, visto que ocorre um risco maior de exposição às complicações do aborto, o que evidencia a necessidade de maiores orientações de caráter preventivo e educacional, principalmente no âmbito das escolas (ARAÚJO et al., 2016; CARVALHO; DIAS et al., 2015; PAES, 2014).

Ainda se observam, nos dias atuais, desinformação e desconhecimento sobre o preservativo feminino. Fatores como maior custo dificultam a sua comercialização e ampla divulgação nos serviços de saúde e farmácias. Os aspectos culturais de dominação masculina também funcionam como empecilhos para o processo de negociação e autonomia feminina (GOMES et al., 2011; GONÇALVES et al., 2013; MENDES et al., 2011; THEOBALD et al., 2012).

Por esses motivos, é importante evidenciar que a camisinha feminina é um método seguro de contracepção e prevenção de DSTs, proporcionando maior autonomia às mulheres, para que tenham relações sexuais com proteção, dispensando a necessidade de ereção peniana para sua colocação. Ademais, é bem lubrificada, podendo ser introduzida horas antes da relação sexual, além de ampliar a sensação de prazer feminino, tendo em vista o contato do anel externo com o clitóris (GOMES et al., 2011; GONÇALVES et al., 2013; MENDES et al., 2011; THEOBALD et al., 2012).

O maior conhecimento da camisinha masculina, por parte dos adolescentes da escola, pode ser resultado de uma maior divulgação do uso dessa camisinha pela mídia, atrelado às campanhas nas datas comemorativas, como Carnaval, Dia dos Namorados e Dia Nacional de Combate à AIDS, de forma que é muito difícil um adolescente desconhecer a função e a introdução de um preservativo masculino (GOMES et al., 2011).

A discussão da temática sexualidade, para quem se vê diante de uma sala de aula, pode trazer inquietudes e desconfortos, pois trata da vida e de comportamentos íntimos do outro, perpassando pelo imaginário popular de alunos e educadores, provocando um sentimento de estranheza. Logo, analisando o papel formador da escola, o processo participativo de reflexão e ação da pessoa sobre o mundo para transformá-lo deve contribuir para a formação de um sujeito crítico capaz de fazer escolhas conscientes e buscar respostas para as suas questões (FREIRE, 1996).

A escola, ao partir para o entendimento de que a relação entre educando e educador precisa ter empatia e afeto, na qual o adolescente constrói seus significados e define suas percepções de realidade, ocupará um papel diretivo necessário para educar e transformar, levando a uma ruptura com o modelo vigente de educação bancária, ainda existente na atualidade (FREIRE, 1996).

Portanto, o trabalho reflexivo com oficinas dinâmicas torna-se uma oportunidade de o educando vislumbrar na escola uma fonte mais segura de obtenção das informações que ele procura e para as quais quer respostas. É nesse prisma, com inserção em campos escolares, sob as premissas da promoção à saúde, que as oficinas podem revelar-se como espaços interativos de um agir educativo que se preocupa com a formação de sujeitos através de projetos pedagógicos voltados para o direito à vida.

\section{Conclusão}

As atividades grupais constituem-se em uma forma privilegiada de facilitar a expressão de sentimentos, a troca de informações e experiências, bem como a busca por soluções. A partir dos resultados expressos, com os objetivos propostos pela pesquisa atingidos, fica evidente a necessidade de ênfase maior na educação sobre saúde sexual e reprodutiva nas escolas, abordando o tema de forma alternativa ao modelo tradicional de educação depositária, que não possibilita ao estudante, nem ao adolescente, a efetiva socialização do saber.

Nesse contexto, e com o intuito de fornecer ao adolescente uma fonte mais segura de informações e inseri-lo em atividades de promoção à saúde, é que a escola precisa proporcionar espaços para a construção do conhecimento a partir das experiências e vivências trazidas, rompendo com o modelo clássico da posição do educador. Logo, os tabus, as crenças e os mitos da sexualidade na adolescência precisam ser discutidos através de estratégias que reconheçam a capacidade do adolescente em pensar e atuar, sem tirar a sua responsabilidade pela própria sexualidade.

A oficina realizada evidenciou bem essa realidade ao propiciar um espaço dialógico em grupo sobre a 
sexualidade na adolescência, valorizando a voz dos adolescentes no contexto escolar. Isso é importante para o desenvolvimento de estratégias que busquem maior aproximação entre estudantes e professores, com o intuito de desenvolver um diálogo mais aberto e construtivo sobre as temáticas mais difíceis de serem trabalhadas, uma vez que envolvem tabus da sociedade.

É importante ressaltar também que, para os profissionais de saúde, a oficina foi uma experiência interessante para se repetir em outras ocasiões, pois promoveu educação em saúde nos ambientes escolares, nos quais, muitas vezes, o alcance desse público para trabalhar questões sobre essa temática é árduo. Trata-se, também, de um momento inovador, que deve ser repetido em outras escolas, para abranger e sanar as dúvidas de mais adolescentes, uma vez que, geralmente, atividades de educação permanente são realizadas nos ambientes de saúde.

Assim, a busca por uma educação mais holística e reflexiva, arrolada em princípios mais humanos e solidários, que preparem os educandos para a vida, fomentando uma sociedade mais crítica, poderá ampliar os horizontes para uma plenitude de direitos, na qual a sexualidade seja preservada, diminuindo o estigma, a discriminação e a violência tão prevalentes na sociedade.

\section{Referências}

ARAÚJO, A. K. L.; SILVA JÚNIOR, F. J. G.; ARAÚJO FILHO, A. C. A.; NERY, I. S.; MONTEIRO, C. F. S. Perfil de mulheres que vivenciaram complicações decorrentes do aborto: evidências da literatura científica brasileira. Revista Interdisciplinar, Teresina, v. 9, n. 1, p. 224-233, 2016. Disponível em: <http://revistainterdisciplinar.uninovafapi. edu.br/index.php/revinter/article/view/491/pdf_301>. Acesso em: 8 maio 2016.

BRASIL. Lei 6.202 de 17 de abril de 1975. Atribui à estudante em estado de gestação o regime de exercícios domiciliares. Disponível em: <http://www.planalto.gov.br/ ccivil_03/leis/1970-1979/L6202.htm>. Acesso em: 26 mar. 2016.

BRASIL. Ministério da Saúde. Secretaria de Atenção à Saúde. Departamento de Ações Programáticas Estratégicas. Marco teórico e referencial: saúde sexual e saúde reprodutiva de adolescentes e jovens. Brasília, 2007a. (Textos Básicos de Saúde, Série B.). Disponível em: <http://bvsms.saude.gov. br/bvs/publicacoes/07 0471 M.pdf $>$. Acesso em: 14 maio 2016.
BRASIL. Ministério da Saúde. Secretaria de Atenção à Saúde. Departamento de Ações Programáticas Estratégicas. Direitos sexuais, direitos reprodutivos e métodos anticoncepcionais. Brasília: Ministério da Saúde, 2009. (Direitos Sexuais e Direitos Reprodutivos, n. 2). Disponível em: <http://bvsms.saude.gov.br/bvs/publicacoes/direitos_ sexuais_reprodutivos_metodos_anticoncepcionais.pdf $>$. Acesso em: 14 maio 2016.

BRASIL. Ministério da Saúde. Secretaria de Atenção à Saúde. Saúde integral de adolescentes e jovens: orientações para a organização de serviços de saúde. Brasília, 2007b. Disponível em: <http://bvsms.saude.gov.br/bvs/publicacoes/ saude_adolescentes_jovens.pdf > . Acesso em: 14 maio 2016.

CARVAlHO, S. M.; PAES, G. O. As experiências de mulheres jovens no processo do aborto clandestino: uma abordagem sociológica. Saúde e Sociedade, São Paulo, v. 23, n. 2, p. 548-557, 2014. Disponível em: <http://www.scielo. br/pdf/sausoc/v23n2/0104-1290-sausoc-23-2-0548.pdf>. Acesso em: 8 maio 2016.

COElHO, R. F. S.; SOUTO, T. G.; SOARES, L. R.; LACERDA, L. C. M.; MATÃO, M. E. L. Conhecimentos e crenças sobre doenças sexualmente transmissíveis e HIV/AIDS entre adolescentes e jovens de escolas públicas estaduais da região oeste de Goiânia. Revista de Patologia Tropical, Goiânia, v. 40, n. 1, p. 56-66, 2011. Disponível em: <https://www.revistas.ufg.br/iptsp/article/ view/13914/8859>. Acesso em: 26 mar. 2016.

COSTA, M. A.; RABELO, N. S.; MORAES, I. C. M.; SIQUEIRA, F. C. M.; CABRAL, E. S. M. Fatores que obstam na comunicação entre pais e filhos adolescentes sobre sexualidade. Revista de Enfermagem da UFSM, Santa Maria, v. 4, n. 1, p. 123-132, 2014. Disponível em: <https:// periodicos.ufsm.br/reufsm/article/view/10216/pdf>. Acesso em: 7 maio 2016 .

DIAS, J. M. G.; OLIVEIRA, A. P. S.; CIPOLOTTI, R.; MONTEIRO, B. K. S. M.; PEREIRA, R. O. Mortalidade materna. Revista Médica de Minas Gerais, Belo Horizonte, v. 25, n. 2, p. 173-179, 2015. Disponível em: <http://www. rmmg.org/artigo/detalhes/1771>. Acesso em: 8 maio 2016.

ECOS COMUNICAÇÃO EM SEXUALIDADE. Bonezinho vermelho. 2014. Disponível em: <https:/www.youtube.com/ watch?v=XT2uLwQoBXk >. Acesso em: 28 mar. 2016.

ECOS COMUNICAÇÃO EM SEXUALIDADE. $X$-salada $e$ pão com ovo. 2013. Disponível em: <https://www.youtube. com/watch? $\mathrm{v}=$ maZsvTxQPR4 $>$. Acesso em: 28 mar. 2016. 
FONSECA, R. M. G. S.; AMARAL, M. A. Reinterpretação da potencialidade das Oficinas de Trabalho Críticoemancipatórias. Revista Brasileira de Enfermagem, Brasília, v. 65, n. 5, p. 780-787, 2012. Disponível em: <http://www. scielo.br/pdf/reben/v65n5/10.pdf>. Acesso em: 7 maio 2016.

FRANCO, M. A. S. Pesquisa-ação: a produção partilhada de conhecimento. Unopar Científica: Ciências Humanas e Educação, Londrina, v. 11, n. 1, p. 5-14, 2010. Disponível em: <http:/www.pgsskroton.com.br/seer/index.php/ensino/ article/view/816/780>. Acesso em: 7 maio 2016.

FREIRE, P. Pedagogia da autonomia: saberes necessários à prática educativa. São Paulo: Paz e Terra, 1996.

GOMES, V. L. O.; FONSECA, A. D.; JUNDI, M. G.; SEVERO, T. P. Percepções de casais heterossexuais acerca do uso da camisinha feminina. Escola Anna Nery Revista de Enfermagem, Rio de Janeiro, v. 15, n. 1, p. 22-30, 2011. Disponível em: <http://bibliobase.sermais.pt:8008/ BiblioNET/Upload/PDF8/005670_Escola\%20Anna\%20 Nery.pdf $>$. Acesso em: 27 mar. 2016.

GONÇALVES, H.; GONZÁLEZ-CHICA, D. A.; MENEZES, A. M. B.; HALLAL, P. C.; ARAÚJO, C. L. P.; DUMITH, S. C. Conhecimento sobre a transmissão de HIV/AIDS entre adolescentes com 11 anos de idade do Sul do Brasil. Revista Brasileira de Epidemiologia, São Paulo, v. 16, n. 2, p. 420431, 2013. Acesso em: <http://www.scielo.br/pdf/rbepid/ v16n2/1415-790X-rbepid-16-02-00420.pdf >. Acesso em: 27 mar. 2016.

HEILBORN, M. L. Por uma agenda positiva dos direitos sexuais da adolescência. Psicologia Clínica, Rio de Janeiro, v. 24, n. 1, p. 57-68, 2012. Disponível em: <http://pepsic. bvsalud.org/pdf/pc/v24n1/05.pdf $>$. Acesso em: 26 mar. 2016.

JONES, D. E. Diálogos entre padres y adolescents sobre sexualidad: discursos morales y medicos en la reproducción de las desigualdades de género. Interface: Comunicação, Saúde, Educação, Botucatu, v. 14, n. 32, p. 171-182, 2010. Disponível em: <http://www.scielo.br/scielo. php? script $=$ sci_arttext\&pid=S1414-32832010000100014>. Acesso em: 20 fev. 2016.

MACEDO, S. R. H.; MIRANDA, F. A. N.; PESSOA JÚNIOR, J. M.; NÓBREGA, V. K. M. Adolescência e sexualidade: scripts sexuais a partir das representações sociais. Revista Brasileira de Enfermagem, Brasília, v. 66, n. 1, p. 103, 2013. Disponível em: <http://search.proquest.com/openview/216a 1e83dfa94f02245956a8d1896e0a/1?pq-origsite=gscholar $>$. Acesso em: 7 maio 2016.
MANTOVANI, G. D.; TRES, B.; SILVA, R. M. M.; MOURA, C. B. Comparação de dúvidas sobre sexualidade entre crianças e adolescentes. Revista Contexto \& Educação, Ijuí, v. 29, n. 92, p. 72-90, 2014. Disponível em: <https:// www.revistas.unijui.edu.br/index.php/contextoeducacao/ article/view/2968/3633>. Acesso em: 7 maio 2016.

MAROLA, C. A. G.; SANCHES, C. S. M.; CARDOSO, L. M. Formação de conceitos em sexualidade na adolescência e suas influências. Psicologia da Educação, São Paulo, n. 33, p. 95-118, 2011. Disponível em: <http://pepsic.bvsalud.org/ pdf/psie/n33/n33a06.pdf $>$. Acesso em: 26 mar. 2016.

MELO, M. C. P.; COELHO, E. A. C. Integralidade e cuidado a grávidas adolescentes na atenção básica. Ciência \& Saúde Coletiva, Rio de Janeiro, v. 16, n. 5, p. 2549-2558, 2011. Disponível em: <http://www.scielo.br/pdf/csc/v16n5/ a25v16n5.pdf>. Acesso em: 27 mar. 2016.

MENDES, S. S.; MOREIRA, R. M. F.; MARTINS, C. B. G.; SOUZA, S. P. S.; MATOS, K. F. Saberes e atitudes dos adolescentes frente à contracepção. Revista Paulista de Pediatria, São Paulo, v. 29, n. 3, p. 385-391, 2011. Disponível em: <http:/www.scielo.br/scielo.php?script=sci_arttext\&pi $\mathrm{d}=\mathrm{S} 0103-05822011000300013>$. Acesso em: 27 mar. 2016.

MINAYO, M. C. S.; DESLANDES, S. F.; GOMES, R. (Org.). Pesquisa social: teoria, método e criatividade. 31. ed. Petrópolis: Vozes, 2012.

MORAES, S. P.; VITALLE, M. S. S. Direitos sexuais e reprodutivos na adolescência. Revista da Associação Médica Brasileira, São Paulo, v. 58, n. 1, p. 48-52, 2012. Disponível em: <http://www.scielo.br/pdf/ramb/v58n1/v58n1a14.pdf $>$. Acesso em: 26 mar. 2016.

MOREIRA, B. L. R.; FOLMER, V. Percepções de professores de ciências e educação física acerca da educação sexual na escola. Experiências em Ensino de Ciências, Cuiabá, v. 10, n. 10, 2015. Disponível em: <http://if.ufmt.br/eenci/artigos/ Artigo_ID282/v10_n2_a2015.pdf $>$. Acesso em: 23 dez. 2015.

NERY, I. S.; FEITOSA, J. J. M.; SOUSA, A. F. L.; FERNANDES, A. C. N. Abordagem da sexualidade no diálogo entre pais e adolescentes. Acta Paulista de Enfermagem, São Paulo, v. 28, n. 3, p. 287-292, 2015. Disponível em: <http://www.scielo.br/pdf/ape/v28n3/19820194-ape-28-03-0287.pdf>. Acesso em: 7 maio 2016.

PAPALIA, D. E.; FELDMAN, R. D. Desenvolvimento humano. 12. ed. Porto Alegre: Artmed, 2013. 
PIROTTA, K. C. M.; BARBOSA, R.; PUPO, L. R.; UNBEHAUM, S.; CAVASIN, S. Programas de orientação sexual nas escolas: uma análise das lacunas na implementação de políticas públicas a partir da percepção dos alunos da rede municipal de ensino de São Paulo. Revista Gestão \& Políticas Públicas, São Paulo, v. 3, n. 1, p. 190-210, 2013. Disponível em: <http://www.revistas.usp.br/rgpp/article/ view/97893>. Acesso em: 7 maio 2016.

QUIRINO, G. S.; ROCHA, J. B. T. Educação sexual em uma escola pública de Juazeiro do Norte/CE: percepção dos adolescentes. Acta Scientiae, Canoas, v. 14, n. 1, 2012. Disponível em: <http://www.periodicos.ulbra.br/index.php/ acta/article/view/215/200>. Acesso em: 23 dez. 2015.

SAVEGNAGO, S. D. O.; ARPINI, D. M. Diálogos sobre sexualidade na família: reflexões a partir do discurso de meninas. Psicologia Argumento, Curitiba, v. 32, n. 76, p. $57-$ 67, 2014. Disponível em: <http://www2.pucpr.br/reol/pb/ index.php $/ \mathrm{pa} ? \mathrm{dd} 1=14562 \& \mathrm{dd} 99=$ view $\& \mathrm{dd} 98=\mathrm{pb}>$. Acesso em: 20 fev. 2016.

SILVA JÚNIOR, A. F.; SILVA, M. C. F.; PALHETA, A. S. E.; TEIXEIRA, J. B. G. O inicio da vida sexual de adolescentes escolares de uma comunidade tradicional do município de Inhangapi, Estado do Pará. Amazônia em Foco: Ciência e Tecnologia, Castanhal, v. 4, n. 6, p. 5-17, 2016. Disponível em: $\quad<$ http://revista.fcat.edu.br/index.php/path/article/ viewFile/177/139>. Acesso em: 7 maio 2016.

SILVA, A. K. L. S. Diversidade sexual e de gênero: a construção do sujeito social. Revista do NUFEN, Belém, v. 5, n. 1, p. 12-25, 2013. Disponível em: <http://pepsic. bvsalud.org/pdf/rnufen/v5n1/a03.pdf $>$. Acesso em: 26 mar. 2016.

SILVA, C. G.; PAIVA, V.; PARKER, R. Juventude religiosa e homossexualidade: desafios para a promoção da saúde e de direitos sexuais. Interface: Comunicação, Saúde, Educação, Botucatu, v. 17, n. 44, p. 103-117, 2013. Disponível em: $<$ http://www.scielosp.org/pdf/icse/v17n44/a09v17n44.pdf>. Acesso em: 26 mar. 2016.

THEOBALD, V. D.; NADER, S. S.; PEREIRA, D. N.; GERHARDT, C. R.; OLIVEIRA, F. J. M. A universidade inserida na comunidade: conhecimentos, atitudes e comportamentos de adolescentes de uma escola pública frente a doenças sexualmente transmissíveis. Revista da AMRIGS, Porto Alegre, v. 56, n. 1, p. 26-31, 2012. Disponível em: <http://amrigs.org.br/revista/56-1/0000095572-6_929. pdf $>$. Acesso em: 27 mar. 2016.

VANZIN, R.; AERTZ, D.; ALVES, G.; CÂMARA, S.; PALAZZO, L.; ELICKER, E.; EVANGELISTA, L. A.;
NETO, M. L. Vida sexual de adolescentes escolares da rede pública de Porto Velho-RO. Aletheia, Canoas, v. 41. p. 109120, 2013. Disponível em: <http://pepsic.bvsalud.org/pdf/ aletheia/n41/n41a09.pdf>. Acesso em: 20 fev. 2016.
Recebido em: 04 ago. 2016

Aceito em: 13 abr. 2017 
Da Silva Freire, A. K. et al. 